Accepted (peer-reviewed) version of article

It is authorized for self-archiving after an embargo period of 24 months.

Formatted by the author to enhance readability. 


\title{
Thinking Materially: Cognition as Extended and Enacted
}

\author{
Karenleigh A. Overmann \\ Center for Cognitive Archaeology, \\ University of Colorado, Colorado Springs*
}

\begin{abstract}
Human cognition is extended and enacted. Drawing the boundaries of cognition to include the resources and attributes of the body and materiality allows an examination of how these components interact with the brain as a system, especially over cultural and evolutionary spans of time. Literacy and numeracy provide examples of multigenerational, incremental change in both psychological functioning and material forms. Though we think materiality, its central role in human cognition is often unappreciated, for reasons that include conceptual distribution over multiple material forms, the unconscious transparency of cognitive activity in general, and the different temporalities of metaplastic change in neurons and cultural forms.
\end{abstract}

Keywords: extended mind - enactive cognition - Material Engagement Theory - materiality - literacy numeracy

We think materially: Human cognition is extended, a system including not only brain but body and materiality as components, and enacted, with interactivity among brain, body, and world creating meaning and experience (Clark, 1997; Malafouris, 2013). This rather abstract definition can be at least partially illuminated by the philosophical adage on the sound-making potential of falling trees. Absent someone with appropriate proximity and normally functioning ears and brain, of course, there is only a disturbance of the air, but given a listener, sound occurs. What this implies is that without the brain, there's no perception; what often follows is the idea that perception - and by extension, all cognition-means activity in the brain. But just as there's no perception without the brain, there's also no sound without the tree, whatever caused it to fall, the molecules of air, the waves of energy perturbing them, etc. They are as necessary to perception as the neural activity, though of course the ways in which they contribute to the cognitive system differ.

When materiality and behaviors are considered, it is often in the context of what they do to offload or supplement what the brain does. Human memory, for example, is relatively finite in its capacity, perishable in its duration, and difficult to make public, limitations that can motivate the use of material devices as "cognitive artifacts" (Hutchins, 1999). A classic illustration is that of Inga and Otto, fictive individuals with different forms of memory: Inga memorizes and subsequently recalls an address, which Otto writes in a notebook for later consultation (Clark \& Chalmers, 1998; Clark, 2008). Such artifacts have a long history: Notched bones from the Abri Cellier rockshelter dated to about 28,000 years ago may have once a comprised a tally (Marshack, 1991). While artifacts like Otto's notebook can mitigate organic limitations in accumulating, storing, and sharing information, such devices are often regarded as external, ancillary repositories for mental content, a depiction that renders them more passive than they actually are and obscures attributes like their agency in shaping our behavior. Material properties

\footnotetext{
${ }^{*}$ Correspondence concerning this article should be addressed to Karenleigh A. Overmann, Center for Cognitive Archaeology, University of Colorado, Colorado Springs, 1420 Austin Bluffs Pkwy, Colorado Springs, CO 80918, USA. Email: karenleigh.overmann@keble.oxon.org.
} 
constrain our potential for interactive behaviors (simply, what materiality is influences what we can do with it) and necessitate behavioral investment (as things degrade through use we must actively restore or lose them) (Hodder, 2012; Malafouris, 2013). Otto's notebook holds just what can be written on its pages, persists only while it isn't damaged, lost, tampered with, and he retains the ability to read; he must also remember to consult it, periodically recopy content onto replacement pages, buy new pens, etc.

Another classic example is the cane used by a blind man (since Otto and Inga have names, let's call him Roy). The cane extends Roy's sense of touch to its tip, enabling him to navigate by becoming an integral part of both his perception and his body (Bateson, 1972; Malafouris, 2008; Merleau-Ponty, 2012). In these characteristics, Roy's cane may seem more clearly an instance of extended and enactive cognition compared to Inga's recollection or Otto's notebook, in that it involves overt, unambiguous, and ongoing psychological-behavioral-material interactivity (in contrast, Inga's recollection does not overtly or unambiguously involve materiality, Otto's infrequent consultation of his notes does not comprise ongoing interactivity, etc.). Arguably, however, incorporating notebook and cane as integral components of memory and perception makes both examples of extended cognition; similarly, using notebook and cane to create meaning and experience makes them enactive. Indeed, without materiality, the behaviors that engage it, and the psychological capabilities and behavioral options it enables, the world would be quite different for Inga, Otto, and Roy. Their use of materiality enacts their world.

The idea that materially is integral to human cognition must be placed into historical context because identifying even the brain with cognition is a relatively recent and not uncontroversial development. Franz Joseph Gall, for example, is now remembered more for phrenology, the pseudoscience wherein bumps on the skull were held to govern aspects of personality and cognitive dispositions, than his notion the brain had something to do with mental functions (Gall, 1835). Admittedly, Gall did not much develop the latter aspect of his work because at the time the idea that brain and mind were related was not just revolutionary but heretical. What he did write about the brain's involvement in mental functions certainly got him into trouble: Between 1802 and 1817, his writings were suppressed by the Church and got him fired and driven from cities and countries (Tovino, 2007), and he was even reportedly excommunicated over them (Moscati, 1832). The established, permitted view of the time equated mind with an immaterial soul whose existence was both religiously enforced and philosophically attested (e.g., as Descartes famously divided mind from brain as ontologically distinct substances).

If an idea that was thoroughly rejected a mere two centuries ago is now widely accepted, there nonetheless remains a Cartesian divide between mind and materiality that can and should be challenged (Malafouris, 2013). Why take this perspective? Going back to the question about sound, the falling tree can also (wrongly) imply that perception is mere (passive) presence. To the contrary, perception not only involves world and body as well as brain (i.e., extension), making sense of the world is "inherently active" (enaction): Bodies and behaviors engage the world "in transformational and not merely informational interactions" (di Paolo, Rohde, \& de Jaegher, 2010, p. 39). Transformational interactions occur at multiple levels: neuronal responses to environmental stimuli, physiological characteristics that influence stimuli salience, behaviors that change what stimuli are available, etc. Such interactivity determines experience and meaning; that is, doing and thinking are the same phenomenon, even if it may not seem to us that they are. Further, of all known species, ours is uncommonly adapted to incorporate materiality into our transformational activities. That is, we don't just hear trees fall, chop them down, or 
make tools of twigs, things that beavers and chimps can do; we also use wood to build instruments and create music, using materiality to accumulate social knowledge and influence communal behaviors, interface what a society knows and an individual learns (Haas, 1996), and distribute cognitive effort over space and time (Hutchins, 1995).

Even more importantly, our interactions with materiality have the potential to change our psychological functioning. Listening to music affects mood, for example, and practicing an instrument is associated with functional and structural changes in the brain (Gaser \& Schlaug, 2003; Nayak, Wheeler, Shiflett, \& Agostinelli, 2000). Over longer (cultural and evolutionary) spans of time, changes in psychological processing enable new behaviors with materiality, which can be manipulated thereby into novel forms that can stimulate further change in brains (e.g., literacy and numeracy, as will be discussed). However, since archaic brains cannot be subject to the kinds of experimental protocols available with living brains, investigating how cognition changes over cultural and evolutionary spans of time necessitates new methods in which diachronic change in the material record is examined for what it might indicate about change in associated behaviors and psychological processes, interpreted using criteria based on neurological function and form as understood by cognitive psychology and neuroscience (Wynn, 2002).

This method is not reverse engineering, which argues backward from a psychological ability to its possible evolutionary function, as change in culture and technology can be faster and subject to more complex pressures than just natural selection (Coolidge \& Wynn, 2009). Nor does it necessarily assume a ratchet effect, in which cultural developments accumulate in a way that may preclude retrograde change (Basalla, 1988; Tomasello, Kruger, \& Ratnet, 1993), since cognitive change can be both non-random and non-directional. Further, behaviors and brains change too, dimensions often missed when technology is the focus. In viewing cognition as extended and enacted, positions adopted by Material Engagement Theory, the emphasis is on how behaviors with materiality can yield change in psychological processing, opening up possibilities (not necessarily realized) for further change in behaviors and materiality-in other words, how tools make minds (Malafouris, 2013).

\section{Literacy}

Writing is thought to have been independently invented perhaps four times, in Mesopotamia, Egypt, China, and Mesoamerica. Mesopotamia is typically credited with being first, around 3200 BC. Given their geographic and temporal proximity, Egypt (ca. 3100 BC) and China (ca. 1200 BC) might represent cultural diffusion, rather than invention. Mesoamerica, of course, is far enough away in space and time (ca. $600 \mathrm{BC}$ ) to be considered independent. While writing may have been invented, literacy wasn't, nor could it have been since there was no idea of it to act as goal. Rather, literacy developed through incremental change in brains, behaviors, and materiality accumulated over multiple generations under conditions of sustained social support for the material engagement that is writing. In investigating how this occurred, it is important to point out that the material record of Mesopotamia has the detail and extent needed to correlate material change with change in behaviors like handwriting and the psychological processing involved in reading and writing, and that the behavioral and psychological dimensions of literacy are understood well enough to provide reliable criteria. Arguably, as literacy does not exist without its material form or the behaviors that engage it, it is unambiguously extended and enactive, making its material change particularly likely to represent change in its behavioral and 
psychological components. Also, since literacy occurred fairly recently in terms of human cognitive evolution, there are minimal issues in comparing archaic brains to living ones: Certainly, we are talking about the same species, with similar behaviors under similar conditions, giving the insights of cognitive psychology and neuroscience specific relevance to understanding diachronic material change.

Given the right conditions of training and practice, people today can become literate in a few years (Pegado, Nakamura, \& Hannagan, 2014), a matter of enculturation into an existing system of literacy that changes behavior and psychological processing. But when writing was first invented some five thousand years ago, not only were brains not literate in the way ours can become, writing was also incapable of expressing language with any fidelity. In fact, the earliest writing was so inexpressive that scholars still aren't sure whether the associated language was Sumerian or Akkadian (while most lean toward Sumerian, credible arguments have been offered in support of both possibilities; see Englund, 1998; Veldhuis, 2014). Acquiring literacy and developing fidelity highlight the idea that both brains and writing must undergo change for literacy to emerge. This is why many centuries intervene between the earliest writing and its use beyond use as commodity labels in accounting, and even more centuries pass before writing becomes extensible to multiple discursive applications.

The earliest writing and reading involved this-means-that associations between material signs (simple pictures and figures) and semantic meanings or phonetic sounds (Figure 1). But when used to represent words, pictures and figures are somewhat ambiguous: For example, a picture of a head can mean head, person, or capital. Some way of specifying which word is meant is needed (this is one of the key differences between representing words and representing quantity: three of something may be ambiguous regarding the something but not its quantity; Overmann, 2016a). Though not literate in our sense, such writing and reading nonetheless represented dynamic interactivity between brains, bodies, and materiality: As hands moved to mark signs on clay, eyes watched the productive movements and read the resultant signs, fostering greater coordination between hands and eyes and teaching brains to recognize and recall signs and associated lexical meanings. Over the next several centuries, this psychologicalbehavioral-material interactivity reorganized brains, enabling changes in behaviors and materiality to emerge, with the result that writing became increasingly able to express language with fidelity. Literacy would ultimately emerge as a change to the cognitive system.

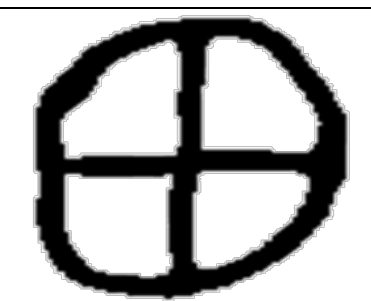

\section{ungulate}

Figure 1. (Left) Quartered disk used to signify "ungulate” (e.g., sheep, cattle) in proto-cuneiform. (Right) The word "ungulate" in alphabetic script. Understanding either involves reading, but the literacy involved in reading the word at right differs from the "this-means-that" association involved in understanding the sign at left. Sign adapted from the Cuneiform Digital Library Initiative.

Contemporary neuroscience knows a lot about the neural activity that differentiates a brain that is literate from one that is not (Dehaene et al., 2010; Dehaene, Cohen, Morais, \& 
Kolinsky, 2015; Nakamura et al., 2012; Perfetti, 2003; Perfetti \& Tan, 2013). Part of the fusiform gyrus in the temporal lobe, which evolved to recognize faces and objects, becomes trained to recognize written characters as if they were objects - through combinations of their local and global features (Cohen \& Dehaene, 2004; Vogel, Petersen, \& Schlaggar, 2014). Once trained, this part of the fusiform gyrus is known as the Visual Word Form Area, and its ability to become trained in reading is cited as an example of neuronal recycling, in which an existing brain function has sufficient plasticity to respond to and become co-opted for a cultural invention (Dehaene \& Cohen, 2007, 2011). A literate brain is also characterized by coordination between the Visual Word Form Area and the parts of the brain that control handwriting and produce and comprehend speech (respectively, Exner's Area in the middle frontal gyrus; Broca's Area, inferior frontal gyrus; and Wernicke's Area, superior temporal gyrus) (Pegado et al., 2014).

Handwriting (as opposed to other forms of manipulating materiality to represent information, like shaping clay into three-dimensional figures or carving signs into stone) was critical to developing literacy. Across languages, the word writing originated in verbs like scratch, incise, and paint (Senner, 1989). Today handwriting is understood to improve fine motor skills, hand-eye coordination, recall of written material, recognition of signs, and tolerance for character ambiguity (i.e., sloppy handwriting) (James \& Engelhardt, 2012; Longcamp, Zerbato-Poudou, \& Velay, 2005; Mueller \& Oppenheimer, 2014; Sülzenbrück, Hegele, Rinkenauer, \& Heuer, 2011). It forms associations between visual signs and the meanings and sounds of language through the coordination between the Visual Word Form Area and Exner's/Broca's/Wernicke's Areas. Most importantly for the development of literacy, handwriting represented a continual tinkering with, and adjustment of, the materiality stimulating the psychological processes engaged in writing and reading (Overmann, 2016a). Social conditions in the late fourth millennium were perfect for this continual tinkering: Mesopotamia was a state-level bureaucracy with massive administrative requirements (Englund, 1991, 2001; Nissen, Damerow, \& Englund, 1993). Scribes wrote and read, hours per day and days for years, the same simple characters with this-means-that associations, interactivity that began to reorganize their brains.

As handwriting behavior continued, fusiform gyri started to become trained in recognizing signs by their features and coordinating with brain regions controlling handwriting and speech. By 3100 BC, sign production became more efficient as wedge-shaped impressions made by stylus displaced the drawing of curved lines (Cooper, 1996; Nissen et al., 1993), and over the next several centuries, wedge order became standardized, enhancing lexical retrieval (Bramanti, 2015; Giovanni, 1994; Taylor, 2015). As signs became recognized by their local and global features, there was less need for them to retain their original iconic forms, so they became increasingly less depictive and were ultimately simplified (Nissen et al., 1993; StudeventHickman, 2007). Scribes also started modifying signs for words with clues to the intended meanings and sounds (e.g., determinatives, word order, syllables, etc.), and by the beginning of the third millennium, these were sufficient to identify the language as Sumerian (Cooper, 1996). As signs became more specific, their recruitment of Broca's and Wernicke's Areas for semantic, syntactic, and phonological functions would have intensified. Additional incremental change can be discerned across seven dimensions: lexicography, organization, syntax, orthography, applications, curriculum, and language expressiveness (Overmann, 2016a).

By the start of the Old Babylonian period (ca. 2000 BC), Mesopotamian writers stopped splitting words between lines of text (Cooper, 2004), suggesting that the recognition of complex 
signs may have been enhanced by contiguity. They developed a cursive script (i.e., script characterized by "abbreviated signs, crowded writing, and unclear sign boundaries"; Veldhuis, 2011, p. 72), demonstrating that object-recognition processing now tolerated a high degree of ambiguity in character form. They extended writing to all sorts of new discursive applications (Veldhuis, 2014), demonstrating an ability to grapple with the ideas writing expressed, rather than the mechanics of its production. Finally, they implemented a formalized curriculum for training scribes (Krispijn, 2012; Veldhuis, 2014), signifying that writing had become opaque without trained object-recognition processing. The amount and rate of change across the seven dimensions also decrease around this same time. These developments suggest that psychological processing, behavior, and the material form of writing had changed through their interactivity sufficiently that Mesopotamian literacy had finally begun to resemble our own, about fifteen hundred years after the first simple pictures and figures were written by hand.

This is not to say Old Babylonian literacy was the same as ours; in the millennia that followed, literacy continued to change, to become widespread, multimedia, digital, high speed, and emoji enhanced. But forget for the moment that literacy subjects language and ideas to analysis, communicates them across space and time (Donald, 1991; Olson, 1994, 2013), and challenges matters of textual authority and authorial presence (Deleuze \& Guattari, 1987; Derrida, 1974). Instead, consider only its material dimension. The materiality of writing and its behavioral engagement are integral to literate reading and writing. It engages specific behavioral abilities and psychological capacities: handwriting; hand-eye coordination; object-recognition processing; interregional brain coordination. Through generations of tinkering and adjustment, the material form becomes increasingly capable of eliciting particular behavioral and psychological responses. Today the material component of literacy embodies and makes available the changes incrementally accumulated by past brains, bodies, and materiality; acts as a medium for recreating those changes in present individuals; and, through mechanisms like malleability and contrasts of form and structure, affords possibilities for realizing future change.

\section{Numeracy}

Another example of long-term change resulting from interactivity between brains, bodies, and materiality is numeracy, the cognitive system for numbers. Like literacy, numeracy is a process of multigenerational, incremental change in both the materiality used to represent and manipulate numbers and the psychological processes they engage. Numeracy illuminates important additional aspects of the function of materiality in human cognition, as will be discussed. In general, the material forms used for representing numbers inform how they are conceptualized. Materiality influences structural characteristics (e.g., linearity) of the cognitive system for numbers, while incorporating new material forms facilitates numerical elaboration. Materially influenced structural characteristics persist across changes in material form, distributing concepts over multiple forms, making concepts seemingly independent of any particular form and enabling them to act as an abstract conceptual domain.

Numbers are concepts of quantity shared by sets of objects (Russell, 1910, 1920). As the perceptual experience of quantity (cardinality) is insufficient for realizing number concepts (Rips, Bloomfield, \& Asmuth, 2008), sets of objects must be manipulated into a form where their shared quantity can be appreciated, familiar as behaviors like pairing and one-to-one correspondence (Overmann, 2015, 2016b). This material engagement bootstraps the process of 
forming concepts of shared quantity because "it is simpler logically to find out whether two collections have the same number of terms than it is to define what that number is" (Russell, 1920, p. 15). Concepts of shared quantity are then represented by one of the sets in the formative comparison, typically the fingers, which is why so many languages have words like digit that mean both finger and number and form the numbers six through nine as five-plus- $x$, and why so many number systems are based on 10 (decimal), 5 (quinary), or 20 (vigesimal) (Comrie, 1989; Greenberg, 1978; Menninger, 1992). Use of the fingers to represent numbers imposes linearity and stable order (Gelman \& Gallistel, 1978), for reasons that include reducing the demand on working memory, facilitating the accessibility of the represented information (an effect word order has in speech), and enhancing lexical recall through conventionalized motor movements (an effect mentioned previously for handwriting in literacy).

Between the late Upper Paleolithic and the Bronze Age (roughly 24,000 to 4000 years ago), peoples in the Ancient Near East counted with fingers, tallies, tokens, and numerical notations. Finger-counting is attested by characteristic groupings (10, 5, and 20) and compounds (five-plus- $x$ ) in lexical numbers in several of the region's archaic languages (Blažek, 1999; Diakonoff, 1983; Edzard, 1980). Notched bones from the Epipaleolithic Levant may have been used as tallies (Coinman, 1996; Reese, 2002). Small clay tokens were used for accounting in Neolithic Mesopotamia (Amiet, 1972; Damerow, 2007; Schmandt-Besserat, 1992), and numerical notations associated with the development of a complex mathematics by the Bronze Age were written on clay tablets (Chrisomalis, 2010; Høyrup, 2002; Nissen et al., 1993; Postgate, 2013; Robson, 2008). As the materiality changed, the concept of number would have changed too, from equivalences between fingers and objects (finger-counting), to collections whose quantities were related to objects (tallies and one-to-one correspondence) and each other (tokens and bundling, in which ten or six tokens of a lower value were equal to one unit of a higher value), and finally to entities related numerically to other entities (numerical notations and tables), similar but certainly not identical to our concept of number. (Collections and entities can be differentiated as 'two and two are four' and 'two plus two is four,' respectively; see Gowers, 2008.)

Interaction with the material forms for numbers would have changed psychological processing as well. For example, material linearity influences linearity in the so-called mental number line, an internal resource for estimating numerical magnitude (Brannon, 2006; Fischer, 2008; Previtali, Rinaldi, \& Girelli, 2011), and its linearity facilitates the conceptualization of higher quantities in regularized and productive ways (Butterworth, Reeve, Reynolds, \& Lloyd, 2008; Dehaene, Izard, Spelke, \& Pica, 2008; Frank, Everett, Fedorenko, \& Gibson, 2008; Gordon, 2004; Núñez, Cooperrider, \& Wassmann, 2012; Piazza, Pica, Izard, Spelke, \& Dehaene, 2013; Pica, Lemer, Izard, \& Dehaene, 2004; Siegler \& Booth, 2004). Arithmetic and mathematical tasks recruit executive functions like attention and working memory (Bull \& Lee, 2014; Bull \& Scerif, 2001; Van der Ven, Kroesbergen, Boom, \& Leseman, 2012). These in turn increase goal-directed behavior, allowing new behaviors to emerge, like rearranging tokens into new combinations or performing calculations that are more complex. New material combinations, of course, can stimulate further change in psychological processing and behaviors.

Materiality influenced structural characteristics of the cognitive system for numbers as well. Fingers (Gelman \& Gallistel, 1978) and tallies imposed linearity and stable order that persisted in how the loose tokens were organized. Because they were loose, tokens injected manipulability that enabled the realization of relations between numbers and algorithms for manipulating them (i.e., combining or separating tokens and bundling or debundling them, similar 
to the way an abacus works). With notations, which are fixed, manipulability persisted in the form of new algorithms used to manipulate the relations between numerical representations, something that intensified the need to remember and recall the relations (Overmann, 2016c). Numerical notations also allowed for greater concision in representing numbers, facilitating the development of tables (e.g., tables of multiplicative and reciprocal relations), and garnering the handwriting effects previously discussed for literacy. These would ultimately enable numbers to become conceptualized as entities (rather than collections of objects) related to one another numerically.

The incorporation of new material forms would have enabled the elaboration of number concepts. As new material forms are incorporated into a number system, the highest number counted increases (Divale, 1999; Overmann, 2013a, 2013b). The increase in the availability of exemplars (i.e., more numbers in the number system) tends to increase the likelihood that the relations between numbers will be discovered and explicated (Beller \& Bender, 2011; Bender \& Beller, 2011). Similarly, the increase in exemplars tends to make it more likely that operations on the relations between numbers (e.g., addition, multiplication, complex algorithms, etc.) will be discovered and explicated. Contrasts between older and newer material forms would also have made it more likely that numerical concepts would become elaborated (Overmann, 2016c), as they would have provided opportunities for the brain to do something it does extremely wellrecognize patterns and form categories and abstractions (Clark, 2008; Devlin, 2003).

As structure persists across changes in material form, concepts become distributed over multiple forms. For example, a number like ' 37 ' is distributed across signs for 'three' and 'seven' (i.e., $3 \times 10^{1}$ plus $7 \times 10^{0}$ ), similar to the way it was once distributed across cuneiform notations ( $\$ 44$ ), collections of tokens, tally notches, and fingers (the latter assumes the use of the hands of multiple individuals, suggested by groupings of 10 and 20 in compound number terms in archaic languages; see Blažek, 1999; Wilcke, 2005). Distribution is also implicit in the persistence of older forms, not only in the structure and capabilities they provide, but perhaps in their actual use as well. That is, people enculturated into the Western mathematical tradition still count with their fingers, make tally marks ( $\mathrm{fll}$ ), and use coins (which bear functional similarities to Mesopotamian tokens), along with writing numerical notations on paper and poking them into computers and calculators, and the associated concept of number encompasses all these various ways of representing them, as well as the things to which they're applied-like time, distance, speed, cost, and temperature. In being anchored and stabilized (Hutchins, 2005), structured, and distributed by all these forms of materiality, numbers become independent of any one particular form, an attribute that helps them function as a cognitive technology, structuring how the world is experienced and engaged.

Distribution helps obscure (or make transparent) the role of materiality in the cognitive system for numbers. Interestingly, the material role may be more apparent in an unfamiliar number system. For example, Neolithic token-based accounting has been characterized as mechanical, or concrete in the term once promoted by Piaget; in contrast, Bronze Age numerical notations and calculation methods have been considered abstract, likely because they more closely resemble the familiar Western notations and methods (Damerow, 1996, 2010; SchmandtBesserat, 1992; for a critique, see Chrisomalis, 2005). The concrete-abstract distinction, however, tends to inflate the material aspect of tokens and the symbolic nature of notations, while minimizing tokens' semiotic complexity and notations' materiality (Overmann, 2016b, 2016c), when in actuality Mesopotamian tokens and notations share both material and semiotic qualities. But Bronze Age calculations and methods can also seem concrete when compared to 
contemporary mathematics: Babylonian mathematicians didn't multiply length times width to calculate an area, but used something called a projection that evokes the ropes and rods used to measure fields (Høyrup, 2002). Half the projection was moved to form a larger square, used to calculate total area (Høyrup, 2002) in a method with a palpable sense of manipulating a material model. Understanding how this technique worked isn't as important as recognizing that while it perhaps seems materially dependent and thus rather concrete, it was likely as intuitive and abstract to Babylonian mathematicians as area $=$ length $\times$ width is to us today, suggesting that materiality is most transparent when we use it (e.g., notations written on paper, algorithms to manipulate them) and becomes increasingly opaque as its familiarity decreases.

\section{Metaplastic Change in Co-existing Temporalities}

Literacy and numeracy represent collective remodeling of brain functions through behavioral interactions with material forms, a generative process that allows emergent change in behaviors, material structures, and brain functions and form. The ability of neurons and cultural forms to change through their interaction is metaplasticity (Malafouris, 2010, 2015). The term characterizes both the mechanism of change-interactivity-and the capacity for change in brains, behaviors, and materiality, dimensions that are inseparably entwined in the ongoing creative evolution that is human becoming. When multigenerational processes of collective metaplastic change are described, they sound a lot like genetic change. Certainly, it is reasonable to believe there are genetic underpinnings to literacy and numeracy-things like our capacity for language and appreciating quantity, our ability to extend them across multiple sensory modalities, and our propensity for incorporating materiality as an integral part of our cognitive system. However, literacy and numeracy are not genetic but cultural, and critically depend on social conditions for sustaining and recreating the requisite behaviors and material forms.

Metaplastic change involves differing but co-existing temporalities-neural reactions measured in fractions of seconds and ontogenetic developments that unfold over decades; centuries to millennia and longer for materiality. In the moment-reading these words, for example-it may be difficult to appreciate that the dynamic interactivity of psychological processes, behaviors, and material forms constitutes participation in multigenerational change. Certainly, the material form (printed page, computer display) seems unchanging, and its material agency is often unnoticed. The brain's activity in processing written language is mostly unconscious, as cognition is in general: We don't deliberately perceive objects or form memories or think through the moment-tomoment details of how we will perceive, learn, move, or speak (Kihlstrom, 1987, 1989). And our experience of cognition is, on the whole, individual rather than collective. And yet, literacy was realized through just such in-the-moment interactivity-between individuals and material forms; within communities of practitioners-over millennia. In contrast, page and screen have previous lives as pulp and minerals, and temporalities that span human processes of collection, use, and destruction. Over cultural and evolutionary spans of time, material forms change rapidly, reflecting our technological capabilities for manufacturing, our social capacities for things like trade, our aesthetic sensibilities and creativity, the change in brain function and form. The temporal span is such that our collective cognitive change is generally imperceptible to individual experience, especially change in its psychological dimension.

The different temporalities coexist and connect in the individual, who not only reproduces and transmits his or her enculturated knowledge and skills to social others, but also 
provides a unique variability to the mix - the potential of a different psychological capacity, a different physical characteristic, a different behavioral ability, a different material combination or context. Individual variability admits the potential for innovation that may be reproduced by others. Participation and change occur when these words are read; our cumulative variability is the overall trajectory of change. Our activity is the fabric of human becoming. The different temporalities also connect and coexist in the material. Andy Clark once attributed the swimming efficiency of fish to an evolved capacity for dynamically exploiting the kinetic energy of water (Clark, 1997). Our analogy, Clark said, is language, but it is also material. Materiality bridges the different temporalities, in seeming to change least when we change most, and in changing most rapidly when we cannot see ourselves changing at all.

\section{References}

Amiet, P. (1972). Mémoires de la délégation archéologique en Iran, Tome XLIII, Mission de Susiane (Vol. I). Paris: Librairie Orientaliste Paul Geuthner.

Basalla, G. (1988). The evolution of technology. Cambridge: Cambridge University Press.

Bateson, G. (1972). Steps to an ecology of mind. Chicago, IL: University of Chicago Press.

Beller, S., \& Bender, A. (2011). Explicating numerical information: When and how fingers support (or hinder) number comprehension and handling. Frontiers in Cognition, 2, 1-3.

Bender, A., \& Beller, S. (2011). Fingers as a tool for counting: Naturally fixed or culturally flexible? Frontiers in Psychology, 2, 1-2.

Blažek, V. (1999). Numerals: Comparative etymological analyses and their implications: Saharan, Nubian, Egyptian, Berber, Kartvelian, Uralic, Altaic and Indo-European languages. Brno, Czech Republic: Masarykova Univerzita.

Bramanti, A. (2015). Rethinking the writing space: Anatomy of some early dynastic signs. In E. Devecchi, G. G. W. Müller, \& J. Mynářová (Eds.), Current research in cuneiform palaeography: Proceedings of the workshop organised at the $60^{\text {th }}$ Rencontre Assyriologique Internationale, Warsaw 2014 (pp. 3147). Gladbeck, Germany: PeWe-Verlag.

Brannon, E. M. (2006). The representation of numerical magnitude. Current Opinion in Neurobiology, 16(2), 222-229.

Bull, R., \& Lee, K. (2014). Executive functioning and mathematics achievement. Child Development Perspectives, 8(1), 36-41.

Bull, R., \& Scerif, G. (2001). Executive functioning as a predictor of children's mathematics ability: Inhibition, switching, and working memory. Developmental Neuropsychology, 19(3), 273-293.

Butterworth, B., Reeve, R., Reynolds, F., \& Lloyd, D. (2008). Numerical thought with and without words: Evidence from indigenous Australian children. Proceedings of the National Academy of Sciences of the United States of America, 105(35), 13179-13184.

Chrisomalis, S. (2005). Evaluating ancient numeracy: Social versus developmental perspectives on ancient Mesopotamian numeration. Paper presented at the Annual Meeting of the Jean Piaget Society (Vancouver, British Columbia).

Chrisomalis, S. (2010). Numerical notation: A comparative history. Cambridge: Cambridge University Press.

Clark, A. (1997). Being there: Putting brain, body, and world together again. Cambridge, MA: The MIT Press.

Clark, A. (2008). Supersizing the mind: Embodiment, action, and cognitive extension. New York: Oxford University Press.

Clark, A., \& Chalmers, D. J. (1998). The extended mind. Analysis, 58, 7-19. 
Cohen, L., \& Dehaene, S. (2004). Specialization within the ventral stream: The case for the visual word form area. NeuroImage, 22, 466-476.

Coinman, N. R. (1996). Worked bone in the Levantine Upper Paleolithic: Rare examples from the Wadi al-Hasa, West-Central Jordan. Paléorient, 22(2), 113-121.

Comrie, B. (1989). Language universals and linguistic typology $\left(2^{\text {nd }}\right.$ ed.). Chicago, IL: University of Chicago Press.

Coolidge, F. L., \& Wynn, T. (2009). The rise of Homo sapiens: The evolution of modern thinking. Oxford: Wiley-Blackwell.

Cooper, J. S. (1996). Sumerian and Akkadian. In P. T. Daniels \& W. Bright (Eds.), The world's writing systems (pp. 37-57). New York: Oxford University Press.

Cooper, J. S. (2004). Babylonian beginnings: The origin of the cuneiform writing system in comparative perspective. In S. D. Houston (Ed.), The first writing: Script invention as history and process (pp. 71-99). Cambridge: Cambridge University Press.

Damerow, P. (1996). Prehistory and cognitive development. In M. Killen (Ed.), Invited Lecture at the Twenty-Fifth Annual Symposium of the Jean Piaget Society Berkeley, June 1-June 3, 1995 (pp. 1-37). Berlin: Max Planck Institute for the History of Science.

Damerow, P. (2007). The material culture of calculation: A theoretical framework for a historical epistemology for the concept of number. In U. Gellert \& E. Jablonka (Eds.), Mathematisation and demathematisation: Social, philosophical and educational ramifications (pp. 19-56). Rotterdam: Sense Publishers.

Damerow, P. (2010). Abstraction and representation: Essays on the cultural evolution of thinking. Dordrecht, The Netherlands: Kluwer Academic.

Dehaene, S., \& Cohen, L. (2007). Cultural recycling of cortical maps. Neuron, 56(2), 384-398.

Dehaene, S., \& Cohen, L. (2011). The unique role of the visual word form area in reading. Trends in Cognitive Sciences, 15(6), 254-262.

Dehaene, S., Cohen, L., Morais, J., \& Kolinsky, R. (2015). Illiterate to literate: Behavioural and cerebral changes induced by reading acquisition. Nature Reviews Neuroscience, 16(4), 234-244.

Dehaene, S., Izard, V., Spelke, E., \& Pica, P. (2008). Log or linear? Distinct intuitions of the number scale in Western and Amazonian indigene cultures. Science, 320(5880), 1217-1220.

Dehaene, S., Pegado, F., Braga, L. W., Ventura, P., Filho, G. N., Jobert, A., ... Cohen, L. (2010). How learning to read changes the cortical networks for vision and language. Science, 330(6009), 1359-1364.

Deleuze, G., \& Guattari, F. (1987). A thousand plateaus: Capitalism and schizophrenia. (B. Massumi, Trans.). Minneapolis, MN: University of Minnesota Press.

Derrida, J. (1974). Of grammatology. (G. C. Spivak, Trans.). Baltimore, MD: Johns Hopkins University Press.

Devlin, K. (2003). Mathematics: The science of patterns: The search for order in life, mind and the universe. New York: Henry Holt and Company.

Di Paolo, E. A., Rohde, M., \& de Jaegher, H. (2010). Horizons for the enactive mind: Values, social interaction, and play. In J. Stewart, O. Gapenne, \& E. A. di Paolo (Eds.), Enaction: Toward a new paradigm for cognitive science (pp. 33-87). Cambridge, MA: The MIT Press.

Diakonoff, I. M. (1983). Some reflections on numerals in Sumerian: Towards a history of mathematical speculation. Journal of the American Oriental Society, 103(1), 84-92.

Divale, W. (1999). Climatic instability, food storage, and the development of numerical counting: A cross-cultural study. Cross-Cultural Research, 33(4), 341-368.

Donald, M. (1991). Origins of the modern mind. Cambridge, MA: Harvard University Press.

Edzard, D. O. (1980). Sumerisch 1 bis 10 in Ebla. Studi Eblaiti, III(5-8), 121-127.

Englund, R. K. (1991). Archaic dairy metrology. Iraq, 53, 101-104. 
Englund, R. K. (1998). Texts from the Late Uruk period. In Mesopotamien: Späturuk-Zeit und Frühdynastische Zeit (pp. 15-233). Freiburg, Switzerland: Universitätsverlag.

Englund, R. K. (2001). Grain accounting practices in archaic Mesopotamia. Changing views on ancient Near Eastern mathematics. Berliner Beiträge Zum Vorderen Orient, 19, 1-35.

Fischer, M. H. (2008). Finger counting habits modulate spatial-numerical associations. Cortex, 44(4), 386-392.

Frank, M. C., Everett, D. L., Fedorenko, E., \& Gibson, E. (2008). Number as a cognitive technology: Evidence from Pirahã language and cognition. Cognition, 108(3), 819-824.

Gall, F. J. (1835). On the functions of the brain and of each of its parts: With observations of the possibility of determining the instincts, propensities, and talents, or the moral and intellectual dispositions of men and animals, by the configuration of the brain and head. (W. Lewis Jr, Trans.) (Vol. 1). Boston, MA: Marsh, Capen and Lyon.

Gaser, C., \& Schlaug, G. (2003). Brain structures differ between musicians and non-musicians. The Journal of Neuroscience, 23(27), 9240-9245.

Gelman, R., \& Gallistel, C. R. (1978). The child's understanding of number. Cambridge, MA: The President and Fellows of Harvard College.

Giovanni, F. B. d'Arcais. (1994). Order of strokes writing as a cue for retrieval in reading Chinese characters. European Journal of Cognitive Psychology, 6(4), 337-355.

Gordon, P. (2004). Numerical cognition without words: Evidence from Amazonia. Science, 306(5695), 496-499.

Gowers, T. (Ed.). (2008). The Princeton companion to mathematics. Princeton, NJ: Princeton University Press.

Greenberg, J. H. (1978). Generalizations about numeral systems. In J. H. Greenberg (Ed.), Universals of human language (Vol. 3, pp. 249-295). Stanford, CA: Stanford University Press.

Haas, C. (1996). Writing technology: Studies on the materiality of literacy. New York: Routledge.

Hodder, I. (2012). Entangled: An archaeology of the relationships between humans and things. Malden, MA: Wiley-Blackwell.

Høyrup, J. (2002). Lengths, widths, surfaces: A portrait of Old Babylonian algebra and its kin. New York: Springer.

Hutchins, E. (1995). Cognition in the wild. Cambridge, MA: The MIT Press.

Hutchins, E. (1999). Cognitive artifacts. In R. A. Wilson \& F. C. Keil (Eds.), The MIT encyclopedia of the cognitive sciences (pp. 126-127). Cambridge, MA: The MIT Press.

Hutchins, E. (2005). Material anchors for conceptual blends. Journal of Pragmatics, 37(10), 1555-1577.

James, K. H., \& Engelhardt, L. (2012). The effects of handwriting experience on functional brain development in pre-literate children. Trends in Neuroscience and Education, 1(1), 32-42.

Kihlstrom, J. F. (1987). The cognitive unconscious. Science, 237(4821), 1445-1452.

Kihlstrom, J. F. (1989). Cognition, unconscious processes. In G. Adelman (Ed.), Neuroscience year: Supplement 1 to the encyclopedia of neuroscience (pp. 34-36). Boston, MA: Birkhauser.

Krispijn, T. J. H. (2012). Writing Semitic with cuneiform script: The interaction of Sumerian and Akkadian orthography in the second half of the third millennium BC. In A. de Voogt \& J. F. Quack (Eds.), The idea of writing: Writing across borders (pp. 181-218). Leiden, The Netherlands: Koninklijke Brill NV.

Longcamp, M., Zerbato-Poudou, M.-T., \& Velay, J.-L. (2005). The influence of writing practice on letter recognition in preschool children: A comparison between handwriting and typing. Acta Psychologica, 119(1), 67-79.

Malafouris, L. (2008). Beads for a plastic mind: The “blind man's stick” (BMS) hypothesis and the active nature of material culture. Cambridge Archaeological Journal, 18(3), 401-414. 
Malafouris, L. (2010). Metaplasticity and the human becoming: Principles of neuroarchaeology. Journal of Anthropological Sciences, 88, 49-72.

Malafouris, L. (2013). How things shape the mind: A theory of material engagement. Cambridge, MA: The MIT Press.

Malafouris, L. (2015). Metaplasticity and the primacy of material engagement. Time and Mind, 8(4), 351-371.

Marshack, A. (1991). The roots of civilization: The cognitive beginnings of man's first art, symbol and notation (Revised an.). New York: Moyer Bell Ltd.

Menninger, K. (1992). Number words and number symbols: A cultural history of numbers. (P. Broneer, Trans.). New York: Dover.

Merleau-Ponty, M. (2012). Phenomenology of perception. (D. Landes, Trans.). London: Routledge.

Moscati, M. F. (1832). History and conversion of an anti-phrenologist. The Lancet, 1(480), 213-216.

Mueller, P. A., \& Oppenheimer, D. M. (2014). The pen is mightier than the keyboard Advantages of longhand over laptop note taking. Psychological Science, 25(6), 1159-1168.

Nakamura, K., Kuo, W.-J., Pegado, F., Cohen, L., Tzeng, O. J. L., \& Dehaene, S. (2012). Universal brain systems for recognizing word shapes and handwriting gestures during reading. Proceedings of the National Academy of Sciences of the United States of America, 109(50), 20762-20767.

Nayak, S., Wheeler, B. L., Shiflett, S. C., \& Agostinelli, S. (2000). Effect of music therapy on mood and social interaction among individuals with acute traumatic brain injury and stroke. Rehabilitation Psychology, 45(3), 274-283.

Nissen, H. J., Damerow, P., \& Englund, R. K. (1993). Archaic bookkeeping: Early writing and techniques of economic administration in the ancient Near East. (P. Larsen, Trans.). Chicago, IL: University of Chicago Press.

Núñez, R. E., Cooperrider, K., \& Wassmann, J. (2012). Number concepts without number lines in an indigenous group of Papua New Guinea. PLoS One, 7(4), 1-8.

Olson, D. R. (1994). The world on paper: The conceptual and cognitive implications of writing and reading. Cambridge: Cambridge University Press.

Olson, D. R. (2013). Literacy and the languages of rationality. Pragmatics \& Cognition, 21(3), 431-447.

Overmann, K. A. (2013a). Material scaffolds in numbers and time. Cambridge Archaeological Journal, 23(01), 19-39.

Overmann, K. A. (2013b). Numbers and time: A cross-cultural investigation of the origin and use of numbers as a cognitive technology. Master's thesis, Department of Psychology. University of Colorado, Colorado Springs, CO.

Overmann, K. A. (2015). Numerosity structures the expression of quantity in lexical numbers and grammatical number. Current Anthropology, 56(5), 638-653.

Overmann, K. A. (2016a). Beyond writing: The development of literacy in the Ancient Near East. Cambridge Archaeological Journal, 26(2), 285-303.

Overmann, K. A. (2016b). Number concepts are constructed through material engagement: A reply to Sutliff, Read, and Everett. Current Anthropology, 57(3), 352-356.

Overmann, K. A. (2016c). The role of materiality in numerical cognition. Quaternary International, 405, 42-51.

Pegado, F., Nakamura, K., \& Hannagan, T. (2014). How does literacy break mirror invariance in the visual system? Frontiers in Psychology, 5, 1-5.

Perfetti, C. A. (2003). The universal grammar of reading. Scientific Studies of Reading, 7(1), 3-24.

Perfetti, C. A., \& Tan, L.-H. (2013). Write to read: The brain's universal reading and writing network. Trends in Cognitive Sciences, 17(2), 56-57.

Piazza, M., Pica, P., Izard, V., Spelke, E. S., \& Dehaene, S. (2013). Education enhances the acuity of the 
nonverbal approximate number system. Psychological Science, 24(6), 1037-1043.

Pica, P., Lemer, C., Izard, V., \& Dehaene, S. (2004). Exact and approximate arithmetic in an Amazonian indigene group. Science, 306(5695), 499-503.

Postgate, J. N. (2013). Bronze Age bureaucracy. Cambridge: Cambridge University Press.

Previtali, P., Rinaldi, L., \& Girelli, L. (2011). Nature or nurture in finger counting: A review on the determinants of the direction of number-finger mapping. Frontiers in Psychology, 2, 1-5.

Reese, D. S. (2002). On the incised cattle scapulae from the East Mediterranean and Near East. Bonner Zoologische Beitrage, 50, 183-198.

Rips, L. J., Bloomfield, A., \& Asmuth, J. (2008). From numerical concepts to concepts of number. Behavioral and Brain Sciences, 31(6), 623-642.

Robson, E. (2008). Mathematics in ancient Iraq: A social history. Princeton, NJ: Princeton University Press.

Russell, B. (1910). The theory of logical types. In D. Lackey (Ed.), Essays in analysis (pp. 215-252). New York: George Braziller.

Russell, B. (1920). Introduction to mathematical philosophy ( $2^{\text {nd }}$ ed.). London: George Allen \& Unwin, Ltd.

Schmandt-Besserat, D. (1992). Before writing: From counting to cuneiform (2 vols.). Austin, TX: University of Texas Press.

Senner, W. M. (1989). Theories and myths on the origins of writing: A historical overview. In W. M. Senner (Ed.), The origins of writing (pp. 1-26). Lincoln, NE: University of Nebraska Press.

Siegler, R. S., \& Booth, J. L. (2004). Development of numerical estimation in young children. Child Development, 75(2), 428-444.

Studevent-Hickman, B. (2007). The ninety-degree rotation of the cuneiform script. In J. Cheng \& M. H. Feldman (Eds.), Ancient Near Eastern art in context: Studies in honor of Irene J. Winter by her students (pp. 486-513). Leiden, The Netherlands: Brill.

Sülzenbrück, S., Hegele, M., Rinkenauer, G., \& Heuer, H. (2011). The death of handwriting: Secondary effects of frequent computer use on basic motor skills. Journal of Motor Behavior, 43(3), 247-251.

Taylor, J. (2015). Wedge order in cuneiform: A preliminary survey. In E. Devecchi, G. G. W. Müller, \& J. Mynářová (Eds.), Current research in cuneiform palaeography: Proceedings of the workshop organised at the $60^{\text {th }}$ Rencontre Assyriologique Internationale, Warsaw 2014 (pp. 1-30). Gladbeck, Germany: PeWe-Verlag.

Tomasello, M., Kruger, A. C., \& Ratnet, H. H. (1993). Cultural learning. Behavioral and Brain Sciences, 16(3), 495-552.

Tovino, S. A. (2007). Imaging body structure and mapping brain function: A historical approach. American Journal of Law and Medicine, 33(2\&3), 193-228.

Van der Ven, S. H. G., Kroesbergen, E. H., Boom, J., \& Leseman, P. P. M. (2012). The development of executive functions and early mathematics: A dynamic relationship. British Journal of Educational Psychology, 82(1), 100-119.

Veldhuis, N. (2011). Levels of literacy. In K. Radner \& E. Robson (Eds.), The Oxford handbook of cuneiform culture (pp. 68-89). Oxford: Oxford University Press.

Veldhuis, N. (2014). History of the cuneiform lexical tradition. Münster: Ugarit-Verlag.

Vogel, A. C., Petersen, S. E., \& Schlaggar, B. L. (2014). The VWFA: It’s not just for words anymore. Frontiers in Human Neuroscience, 8, 1-10.

Wilcke, C. (2005). ED Lú a und die Sprache(n) der archaischen Texte. In W. H. van Soldt (Ed.), Ethnicity in ancient Mesopotamia: Papers read at the $48^{\text {th }}$ Recontre Assyriologique International, Leiden, 1-4 July 2002 (pp. 430-445). Leiden, The Netherlands: Netherlands Institute.

Wynn, T. (2002). Archaeology and cognitive evolution. Behavioral and Brain Sciences, 25(3), 389-402. 